\title{
Ferulate, an Active Component of Wheat Germ, Ameliorates Oxidative Stress-Induced PTK/PTP Imbalance and PP2A Inactivation
}

\author{
Eun Mi Koh ${ }^{1, \dagger}$, Eun Kyeong Lee ${ }^{1, \dagger}$, Chi Hun Song ${ }^{1}$, Jeongah Song ${ }^{2}$, Hae Young Chung ${ }^{3}$, \\ Chang Hoon Chae ${ }^{4}$ and Kyung Jin Jung ${ }^{1,5}$ \\ ${ }^{1}$ Bioanalytical and Immunoanalytical Research Group, Korea Institute of Toxicology, Daejeon, Korea \\ ${ }^{2}$ Animal Model Research Center, Korea Institute of Toxicology, Jeonbuk, Korea \\ ${ }^{3}$ Molecular Inflammation Research Center for Aging Intervention (MRCA), College of Pharmacy, Pusan National \\ University, Busan, Korea \\ ${ }^{4}$ Celldi, 2-212 Jeonbuk TechnoPark, Wanju, Korea \\ ${ }^{5}$ Department of Human and Environmental Toxicology, Korea University of Science and Technology (UST), Daejeon, \\ Korea
}

\begin{abstract}
Ferulate is a phenolic compound abundant in wheat germ and bran and has been investigated for its beneficial activities. The aim of the present study is to evaluate the efficacy of ferulate against the oxidative stress-induced imbalance of protein tyrosine kinases (PTKs), protein tyrosine phosphatases (PTPs), and serine/threonine protein phosphatase 2A (PP2A), in connection with our previous finding that oxidative stress-induced imbalance of PTKs and PTPs is linked with proinflammatory nuclear factor-kappa B (NF- $\kappa \mathrm{B})$ activation. To test the effects of ferulate on this process, we utilized two oxidative stress-induced inflammatory models. First, YPEN-1 cells were pretreated with ferulate for $1 \mathrm{hr}$ prior to the administration of 2,2'-Azobis(2-methylpropionamidine) dihydrochloride (AAPH). Second, 20-month-old Sprague-Dawley rats were fed ferulate for 10 days. After ferulate treatment, the activities of PTKs, PTPs, and PP2A were measured because these proteins either directly or indirectly promote $\mathrm{NF}-\kappa \mathrm{B}$ activation. Our results revealed that in YPEN-1 cells, ferulate effectively suppressed AAPH-induced increases in reactive oxygen species (ROS) and NF- $\mathrm{B}$ activity, as well as AAPH-induced PTK activation. Furthermore, ferulate also inhibited AAPH-induced PTP and PP2A inactivation. In the aged kidney model, ferulate suppressed aging-induced activation of PTKs and ameliorated aging-induced inactivation of PTPs and PP2A. Thus, herein we demonstrated that ferulate could modulate PTK/PTP balance against oxidative stress-induced inactivation of PTPs and PP2A, which is closely linked with NF- $\mathrm{BB}$ activation. Based on these results, the ability of ferulate to modulate oxidative stress-related inflammatory processes is established, which suggests that this compound could act as a novel therapeutic agent.
\end{abstract}

Key words: Ferulate, Wheat germ, Oxidative stress, PTK, PTP, PP2A

\footnotetext{
Correspondence to: Kyung Jin Jung, Bioanalytical and Immunoanalytical Research Group, Analytical Research Center, Korea Institute of Toxicology, 141 Gajungro, Yuseong-gu, Daejeon 34114, Korea

E-mail: jungk@kitox.re.kr

${ }^{\dagger}$ The first two authors contributed equally to this work.

This is an Open-Access article distributed under the terms of the Creative Commons Attribution Non-Commercial License (http:// creativecommons.org/licenses/by-nc/3.0) which permits unrestricted non-commercial use, distribution, and reproduction in any medium, provided the original work is properly cited.
}

\section{INTRODUCTION}

Ferulate (4-hydroxy-3-methoxycinnamic acid) is a wellknown phytochemical that has been widely used in maintaining good health and nutrition (1) and has been reported to exert beneficial effects, such as lowering blood glucose levels, diminishing cerebral ischemic injury, and promoting anti-tumor activity (2-4). Other reports have shown that ferulate has the potential ability to treat various abnormal conditions, including cancer, arthritis, and aging (5-7). 
Research continues to investigate ferulate and acquire additional evidence of its powerful activities. Ferulate has been shown to reduce LPS-induced TNF- $\alpha$ and IL-1 $\beta$ expression (8), modulate IL-6 expression (9), and attenuate the inflammatory release of NALP3 (10). These promising outcomes of ferulate originate from its strong antioxidant activity, which was shown to affect the regulation of nuclear factor-kappa B (NF-кB) (11).

During inflammation, NF- $\kappa \mathrm{B}$ plays a critical role in regulating proinflammatory gene expression (12). NF- $\kappa \mathrm{B}$ is an inducible dimeric transcription factor that is comprised of Rel family proteins that bind a consensus sequence motif and is found in all cell types (13). NF- $\mathrm{BB}$ activation is involved in a wide variety of gene expression patterns in response to infection, inflammation, inflammatory disease, cancer, and senescence (14). It is also a well-established redox-sensitive transcription factor that is tightly regulated by redox changes (15). Reactive oxygen species (ROS) interact with the cysteine residues of redox-sensitive signaling molecules, such as transcription factors, protein tyrosine phosphatases, and protein kinases; thus, oxidation of thiol groups on these residues can lead to modifications of the target proteins' biological activities, signaling capacities, immune responses, and additional cell live/dead paradigms (16).

As a part of redox biology, cellular signaling is involved in redox-regulated control of protein tyrosine kinases (PTKs) and protein tyrosine phosphatases (PTPs). Moreover, balancing the activation and inhibition of the reversible oxidation of the active sites on these proteins has emerged as a critical sensor of the redox state (17). Reversible tyrosine phosphorylation of proteins is a key regulatory mechanism in eukaryotic physiology that is catalyzed by kinases and phosphatases (18). Accumulating evidence from cell and animal models has demonstrated PTP oxidation in models of common diseases, such as cancer, metabolic/ cardiovascular disease, immune dysfunction, and age-related diseases $(18,19)$. Moreover, the activation status of the PTK Src as well as that of the transcription factor NF- $\kappa B$ are decisive criteria for the onset of cancer (20). Thus, NF$\kappa \mathrm{B}$ and the expression of its downstream effector genes are also affected by the imbalance of PTKs and PTPs, which was deemed to be the cause of numerous diseases in humans $(16,21)$.

In addition to limiting tyrosine phosphorylation and dephosphorylation, PTKs and PTPs affect serine/threonine phosphorylation by modulating the activities of serine/ threonine protein phosphatases (PP) (22). In the PP family, serine/threonine protein phosphatase 2A (PP2A) has been reported to be closely linked with NF- $\kappa \mathrm{B}$ activation; thus, PP2A is now considered a potential therapeutic target of inflammatory diseases and cancer (23). Some reports have provided evidence that inhibition of pan-tyrosine phosphatase activity by orthovanadate translates to inhibi- tion of PP2A, which would result in the upregulation of cellular physiological responses and proinflammatory genes via $\mathrm{NF}-\kappa \mathrm{B}$ activation $(20,22)$.

Based on these reports, ferulate could be a promising agent for treating NF- $\kappa$ B-related diseases. Despite the status of ferulate as a therapeutic agent against inflammatory diseases, cancer, and aging, the effects of ferulate on the regulation of NF- $\mathrm{BB}$ remain unclear. Therefore, we conducted the present study to elucidate the anti-inflammatory effect (if any) of ferulate using a rat endothelial cell line and aged rat kidneys.

\section{MATERIALS AND METHODS}

Materials. 2,2'-Azobis(2-methylpropionamidine) dihydrochloride (AAPH), a bicinchoninic acid (BCA) protein assay kit, and the BCA protein reagent were purchased from Sigma-Aldrich (St. Louis, MO, USA). 2',7'Dichlorodihydrofluorescein diacetate $\left(\mathrm{H}_{2} \mathrm{DCFDA}\right)$ was purchased from Molecular Probes (Eugene, OR, USA). Fetal bovine serum (FBS) and penicillin-streptomycin were purchased from Gibco (New York, NY, USA). The Lipofectamine 2000 transfection reagent and an Antibody Beacon $^{\mathrm{TM}}$ Tyrosine Kinase Assay kit were purchased from Invitrogen (Carlsbad, CA, USA). A ONE-Glo ${ }^{\mathrm{TM}}$ Luciferase Assay System was obtained from Promega (Madison, WI, USA). Primary antibodies were obtained from Santa Cruz Biotechnology (Santa Cruz, CA, USA). The anti-rabbit IgG-horseradish peroxidase-conjugated antibody was purchased from Cell Signaling Biotechnology (Beverly, MA, USA). 3,6-Fluorescein diphosphate (FDP) and a RediPlate ${ }^{\mathrm{TM}}$ 96 EnzChek ${ }^{\circledR}$ Serine/Threonine Phosphatase Assay kit were acquired from ThermoFisher Scientific (Waltham, MA, USA). An enhanced chemiluminescence (ECL) kit was purchased from Pierce Biotechnology (Rockford, IL, USA).

Animals. Young (7-month-old) and old (20-monthold) male Sprague-Dawley (SD) rats raised in specific pathogen-free conditions were obtained from Samtako (Osan, Korea). Animals were individually housed in polycarbonate cages with wood chip bedding, maintained in a climate-controlled room (temperature: $24^{\circ} \mathrm{C}$, relative humidity: $55 \pm 5 \%$ ) with a 12-hr light/dark cycle, and given feed and tap water ad libitum (AL). The old rats were divided into 3 groups ( $n=4$ per group), such that the mean body weight of the groups was identical. Rats in the control group were provided a diet AL with the following composition: $21 \%$ soybean protein, $15 \%$ sucrose, $43.65 \%$ dextrin, $10 \%$ corn oil, $0.15 \% \alpha$-methionine, $0.2 \%$ choline chloride, $5 \%$ salt mix, $2 \%$ vitamin mix, and 3\% SolkaFloc. Ferulate supplementation was carried out by mixing ferulate at a daily dose of 3 or $6 \mathrm{mg} / \mathrm{kg}$ of body weight into the chow. The respective diets were fed to the rats for 10 days. The animal protocol used in this study was reviewed 
and approved by the Institutional Animal Care and Use Committee at Pusan National University (PNU-IACUC, Approval Number: PNU-2014-0601).

Cell culture. YPEN-1 cells (rat prostate endothelial cells) were obtained from the ATCC (American Type Culture Collection, Manassas, VA, USA). The cells were cultured in Dulbecco's modified Eagle's medium (DMEM) supplemented with $2 \mathrm{mM}$ L-glutamine, antibiotics (100 U/ $\mathrm{mL}$ penicillin and $100 \mu \mathrm{g} / \mathrm{mL}$ streptomycin), and $10 \%$ heatinactivated FBS and incubated at $37^{\circ} \mathrm{C}$ in a humidified atmosphere containing $5 \% \mathrm{CO}_{2}$.

Measurement of intracellular ROS. YPEN-1 cells were seeded into a clear-bottom 96-well plate for tissue culture. After they were incubated overnight, the medium was replaced, and the cells were incubated for $1 \mathrm{hr}$ in the presence or absence of ferulate. Afterwards, all cells were administered $400 \mu \mathrm{g} / \mathrm{mL}$ AAPH for $3 \mathrm{hr}$. The medium was then replaced with fresh serum-free medium. In addition, $12.5 \mu \mathrm{M} \mathrm{H} \mathrm{H}_{2} \mathrm{DCFDA}$ was added and incubated with the cells for $30 \mathrm{~min}$. The fluorescence intensity was measured every $10 \mathrm{~min}$ for $40 \mathrm{~min}$ using the bottom read mode of a SpectraMax M3 (Molecular Devices, Sunnyvale, CA, USA) with excitation and emission wavelengths of 485 and 535 $\mathrm{nm}$, respectively.

Luciferase reporter assay. The $\mathrm{pNF}-\kappa \mathrm{B}-\mathrm{Luc}$ vector was purchased from Clontech Laboratories (Mountain View, CA, USA). A mixture of $0.02 \mu \mathrm{g}$ of plasmid and Lipofectamine 2000 at a 1:1 ratio was prepared, added to each well of a 96-well plate $\left(1 \times 10^{4}\right.$ cells/well $)$, and incubated for $36 \mathrm{hr}$. After replacing the media, ferulate and AAPH were added to the cells for $8 \mathrm{hr}$. Then the luciferase assay was performed at which point reagents from the ONE-Glo Luciferase Assay System were added to the plate according to the manufacturer's instructions. Then the luciferase activity was measured using luminometric analysis on a SpectraMax M3 microplate reader (Molecular Devices).

PTK activity. Protein tyrosine kinase activity in the tissue homogenate and cell lysates was assayed by using the Antibody Beacon ${ }^{\mathrm{TM}}$ Tyrosine Kinase Assay kit according to the manufacturer's instructions. To detect tyrosine kinase activity, samples were prepared in 1x kinase buffer (100 mM Tris- $\mathrm{HCl}, 20 \mathrm{mM} \mathrm{MgCl}_{2}, 2 \mathrm{mM}$ EGTA, $2 \mathrm{mM}$ DTT, and $0.02 \%$ Brij 35; pH 7.5) and mixed with the Antibody Beacon detection complex plus substrate in a 96-well microplate. The ATP reagent was then added to the plate and continuously incubated at the reaction temperature. The fluorescence was measured at multiple time points on a GENios (TECAN, Schweiz AG, Mannedorf, Switzerland) with the excitation and emission wavelengths set at 485 and $535 \mathrm{~nm}$, respectively.
PTP activity. To detect tyrosine kinase activity, samples were prepared in PTP assay buffer $(50 \mathrm{mM}$ Tris- $\mathrm{HCl}$, $2 \mathrm{mM}$ EGTA, $5 \mathrm{mM}$ DTT, and $100 \mu \mathrm{M} \mathrm{CaCl}{ }_{2}$; pH 6.3) and mixed with a $100 \mu \mathrm{M}$ solution of 3,6-fluorescein diphosphate (FDP, a fluorogenic substrate that is highly sensitive to PTP activity) in a 96-well microplate. The plate was incubated at room temperature for $5 \mathrm{~min}$, and then the fluorescence was measured at multiple time points on a GENios with the excitation and emission wavelengths set at 485 and $535 \mathrm{~nm}$, respectively.

PP activity. PP activity was measured by using the RediPlate 96 EnzChek Serine/Threonine Phosphatase Assay Kit (ThermoFisher Scientific) according to the manufacturer's protocol. To detect the PP activity, samples were prepared in PP assay buffer (100 mM Tris- $\mathrm{HCl}, 2 \mathrm{mM}$ EGTA, $5 \mathrm{mM}$ DTT, and $200 \mu \mathrm{M} \mathrm{CaCl}_{2} ; \mathrm{pH}$ 6.0) and mixed with $100 \mu \mathrm{M}$ of 6,8 -difluoro-4-methylumbelliferyl phosphate (DiFMUP, a fluorogenic substrate sensitive to PP) in the 96-well microplate. The plate was incubated at room temperature for $5 \mathrm{~min}$, and then fluorescence was measured at multiple time points on a GENios with excitation and emission wavelengths of 360 and $460 \mathrm{~nm}$, respectively.

Tissue homogenates and cell lysates. To prepare Western blot samples, one gram of kidney was homogenized in $5 \mathrm{~mL}$ of homogenate buffer (100 mM Tris, $20 \mathrm{mM}$ $\beta$-glycerophosphate, $20 \mathrm{mM} \mathrm{NaF}, 2 \mathrm{mM}$ sodium orthovanadate, $1 \mathrm{mM}$ EDTA, $0.5 \mathrm{mM}$ PMSF, $1 \mu \mathrm{M}$ pepstatin, and $80 \mathrm{mg} / \mathrm{L}$ trypsin inhibitor; $\mathrm{pH}$ 7.4) and centrifuged at $900 \times \mathrm{g}$ for $15 \mathrm{~min}$ at $4^{\circ} \mathrm{C}$. The supernatants were then recentrifuged at $12,000 \times \mathrm{g}$ for $15 \mathrm{~min}$ at $4^{\circ} \mathrm{C}$ to yield a pelleted mitochondrial fraction and postmitochondrial supernatant fraction; the latter was used as the cytosolic fraction. For the cell lysates, cells were collected, centrifuged, and rinsed once with PBS. The collected cell pellets were resuspended by using a nuclear and cytoplasmic extraction reagent kit (Thermo Fisher Scientific, Waltham, MA, USA) according to the manufacturer's instructions. Then protein quantification of the tissue homogenates and cell lysates was determined using the BCA protein assay according to the manufacturer's instructions.

Western blot analysis. Homogenized samples were boiled for $5 \mathrm{~min}$ with $2 \mathrm{x}$ sample buffer $(0.125 \mathrm{M}$ Tris- $\mathrm{HCl}$, $4 \%$ SDS, 10\% 2-mercaptoethanol, and $0.2 \%$ bromophenol blue; $\mathrm{pH}$ 6.8). Equivalent amounts of protein from each sample were separated on $10 \%$ acrylamide gels by using SDS-PAGE and transferred to a PVDF membrane at $15 \mathrm{~V}$ for $20 \mathrm{~min}$ in a semi-dry transfer system. The membrane was immediately placed into blocking buffer $(1 \%$ bovine serum albumin in $10 \mathrm{mM}$ Tris, $100 \mathrm{mM} \mathrm{NaCl}$, and $0.1 \%$ Tween $20 ; \mathrm{pH} 7.5$ ) and incubated at room temperature for $1 \mathrm{hr}$. The membrane was then treated with specific pri- 
mary antibodies for $2 \mathrm{hr}$ at $25^{\circ} \mathrm{C}$ followed by the addition of a horseradish peroxidase-conjugated anti-goat antibody (Cell Signaling Technology, Danvers, MA, USA) diluted 1:10000 in Tris-buffered saline/Tween 20 (TBS/T) and another incubation at $25^{\circ} \mathrm{C}$ for $1 \mathrm{hr}$. Antibody labeling was detected using enhanced chemiluminescence (Thermo Fisher Scientific) according to the manufacturer's instructions. Pre-stained protein markers were used to determine molecular weight.

Statistical analysis. One representative western blot from the replicates is shown in the figures; however, we analyzed the relative optical intensity of each corresponding band from three separate experiments. For all other assays, the results are expressed as the mean \pm SD from three separate experiments. The statistical significance of differences among the groups was determined by one-factor ANOVA followed by the protected Fisher's LSD post hoc test. Val-

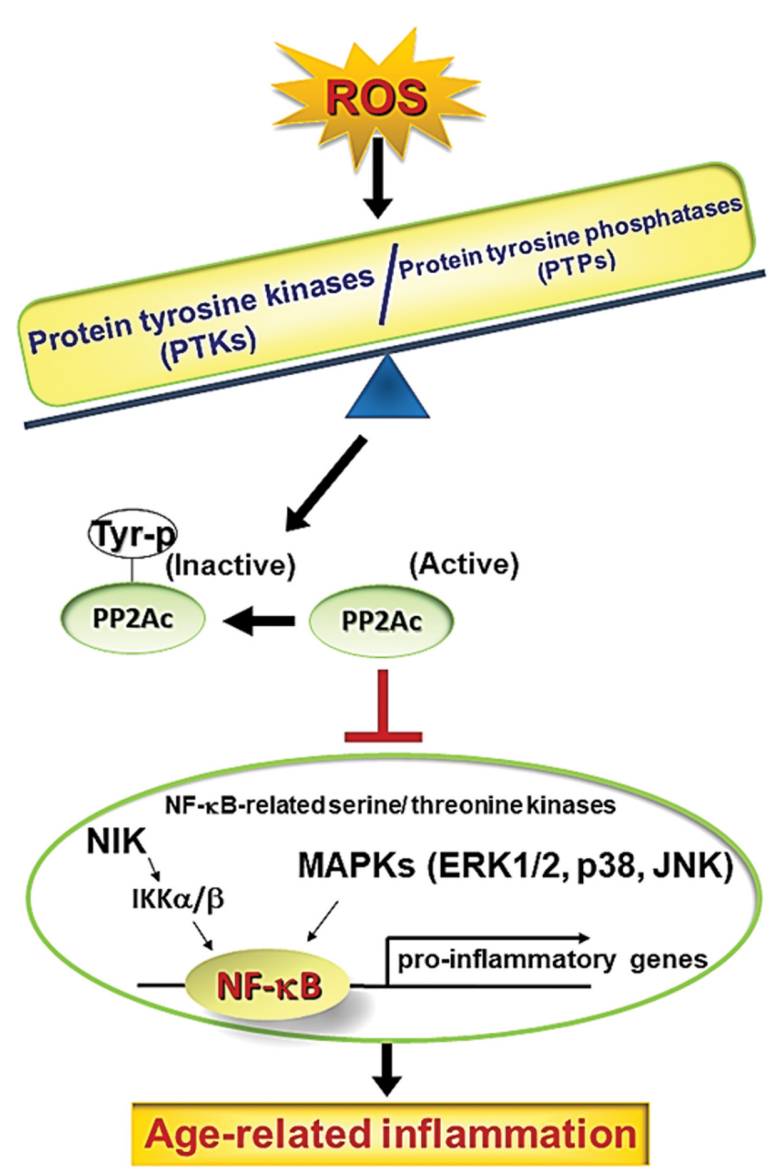

Fig. 1. Schematic diagram of the effect of PTK/PTP imbalance that causes NF- $\kappa B$ activation. Increases in ROS result in changes in the PTK/PTP balance, which promotes inflammatory processes in inflammatory disease and aging models. Furthermore, ROS consequently inactivate PP2A by phosphorylating Tyr307. These alterations lead to NF-kB activation via NIK/ IKKalpha/beta and MAPKs and contribute to the development of molecular inflammation during aging. ues of $p<0.05$ were considered statistically significant.

\section{RESULTS}

Suppressive effect of ferulate on AAPH-induced ROS production and NF- $\kappa$ B activation. In the present study, we aimed to explore the effect of ferulate on oxidative stress-related inflammation due to aging (Fig. 1). AAPH was used to generate oxidative stress to simulate agingrelated conditions in a cell culture model (16). The capacity of ferulate to either eliminate or inhibit the production of intracellular ROS was investigated using DCFDA. Furthermore, this study sought to determine the activity of ferulate on the ROS-related, redox-sensitive transcription factor NF- $\kappa$ B. The results show that ferulate effectively suppressed AAPH-induced ROS levels (Fig. 2A) and NF-

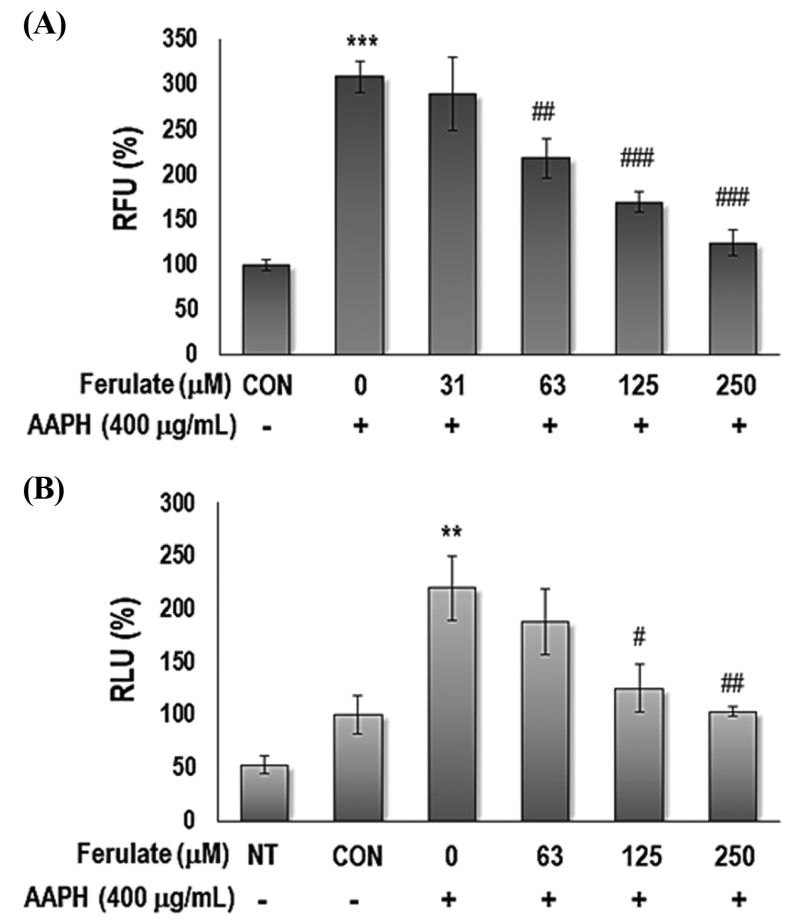

Fig. 2. Effect of ferulate on $A A P H$-induced intracellular ROS generation and NF- $\kappa B$ promoter binding activity. (A) To detect the level of ROS, the relative fluorescence was measured by $\mathrm{H}_{2}$ DCFDA probes. YPEN-1 cells were treated with $31,63,125$, or $250 \mu \mathrm{M}$ ferulate for $1 \mathrm{hr}$ and then incubated with either PBS (vehicle) or $400 \mu \mathrm{g} / \mathrm{mL}$ AAPH. (B) To confirm the inhibitory effect

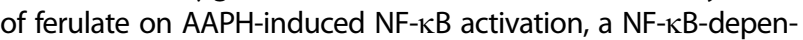
dent luciferase reporter gene assay was performed. YPEN-1 cells were transiently transfected with a plasmid containing the NF- $\mathrm{KB}$ binding motif. After the cells were transfected, they were treated with ferulate and AAPH at the designated concentrations for $8 \mathrm{hr}$, and the luciferase activity was then measured. The results were analyzed using one-way ANOVA: ${ }^{* *} p<$ $0.01,{ }^{* * *} p<0.001$ vs. vehicle-treated group; ${ }^{*} p<0.05,{ }^{\# \#} p<0.01$, $\# p<0.001$ vs. AAPH-treated group. 
$\kappa \mathrm{B}$ activity (Fig. $2 \mathrm{~B}$ ) in a dose-dependent manner.

Modulatory effect of ferulate on AAPH-induced PTK/ PTP imbalance. To clarify the effect of ferulate on the AAPH-induced imbalance of PTKs and PTPs activity, we measured the activity of PTKs and PTPs in YPEN-1 cells.

(A)

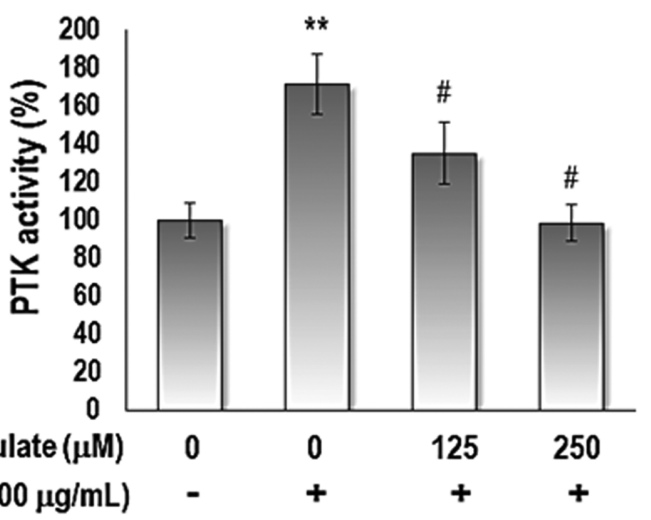

(B)



(C)



Fig. 3. Effect of ferulate on AAPH-induced PTK/PTP activities. Cells were treated with 125 or $250 \mu \mathrm{M}$ ferulate for $1 \mathrm{hr}$, followed by treatment with AAPH for $3 \mathrm{hr}$. (A) PTK and (B) PTP activity was measured to determine $(C)$ the PTK/PTP ratio in AAPH-treated YPEN-1 cells. Each value is presented as the mean $\pm S D$. The results were analyzed using one-way ANOVA: ${ }^{*} p<0.05,{ }^{* *} p<0.01$ vs. vehicle-treated group; ${ }^{*} p<0.05$, ${ }^{\# \#} p<$ 0.01 vs. AAPH-treated group.
Ferulate suppressed AAPH-induced activation of PTK (Fig. 3A) and restored AAPH-induced inactivation of PTP (Fig. 3B), which led to the modulation of the PTK/PTP balance (Fig. 3C).

Next, we determined the total activity of PP. The results indicate that compared with the control treatment, AAPH treatment reduced total PP activity, but ferulate prevented this reduction (Fig. 4A). We aimed to identify the phosphorylation site on PP2A in AAPH-treated YPEN-1 cells

(A)

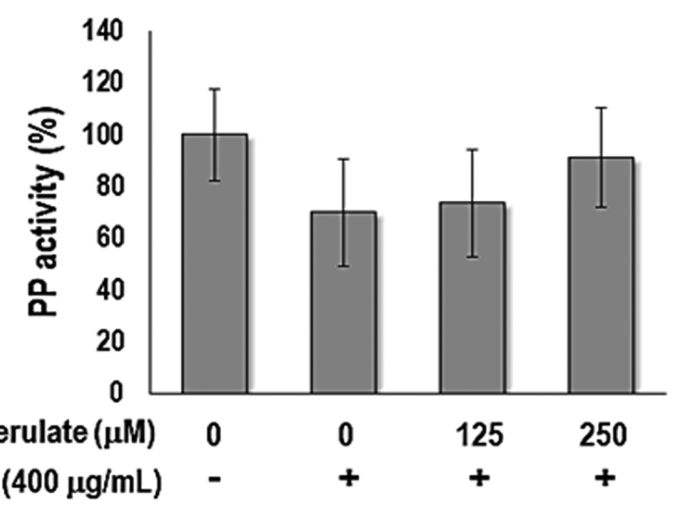

(B)
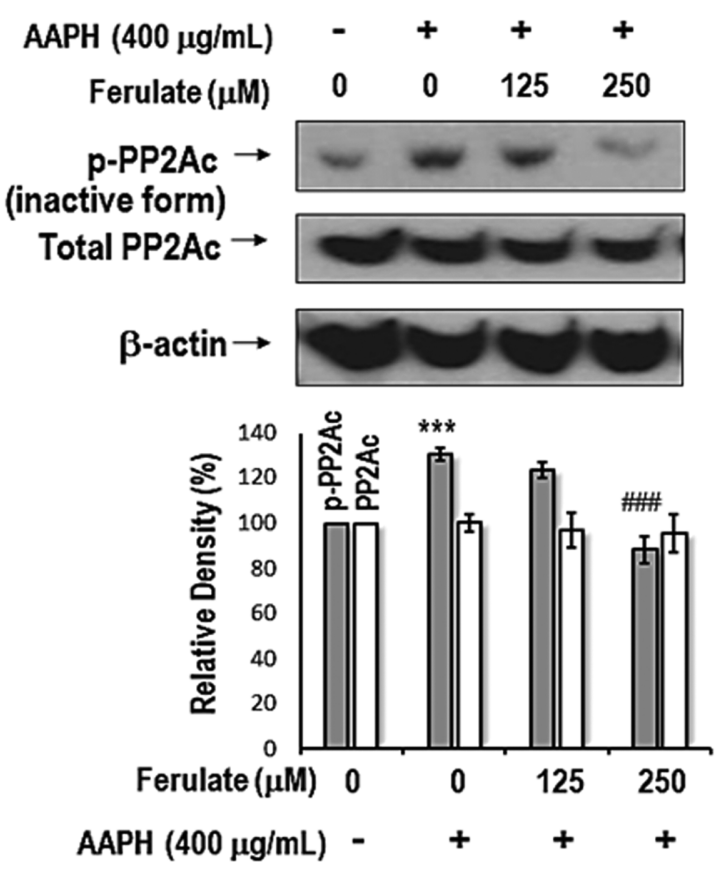

Fig. 4. Effect of ferulate on total PP activity in AAPH-treated YPEN-1 cells. (A) Cell lysates were prepared to measure total PP activity by using a RediPlate 96 EnzChek Serine/Threonine Phosphatase Assay Kit (ThermoFisher Scientific). (B) The levels of phospho-PP2Ac (Tyr307) and total-PP2Ac were detected by western blotting. One representative result from three independent experiments is shown here. $\beta$-Actin was used as the loading control. The results were analyzed using one-way ANOVA: ${ }^{* * *} p<0.001$ vs. vehicle-treated group. ${ }^{\# \#} p<0.001$ vs. AAPH-treated group. 
because phosphorylation of Tyr307 on the catalytic subunit of PP2A (PP2Ac) causes PP2A inactivation (24). As shown in Fig. 4B, ferulate suppressed AAPH-induced phosphorylation of PP2Ac at Tyr307, but there was no change in total PP2Ac expression.

Suppressive effects of dietary ferulate on the PTK/ PTP ratio and PP activity in kidneys from aged rats. We explored the effect of ferulate on the PTK and PTP activity in kidney homogenates from aged rats. Because aged kidney tissues are a model for accumulated oxidative stress, PTK/PTP imbalance, and NF- $\mathrm{KB}$ activation, we selected this model to determine the effect of ferulate on PTK and PTP activity. As shown in Fig. 5, ferulate

(A)

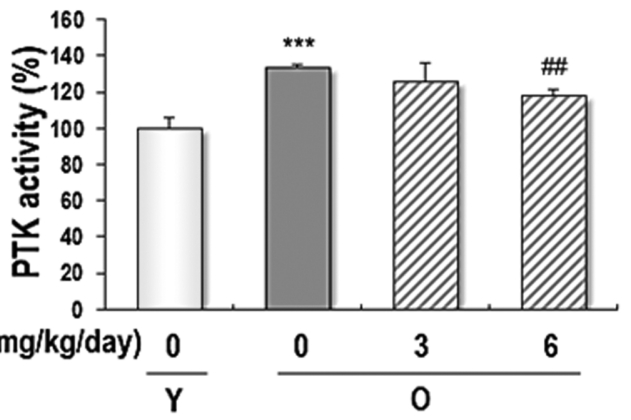

(B)

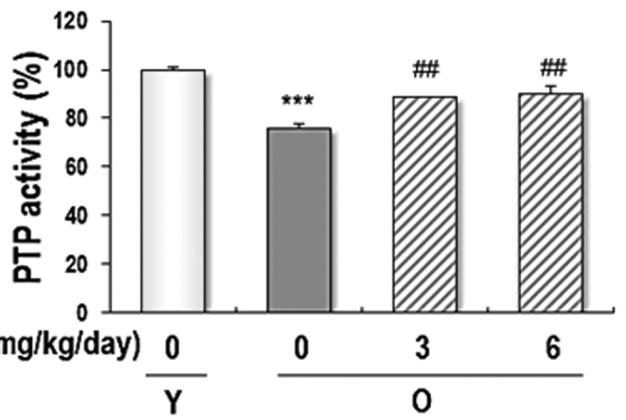

(C)

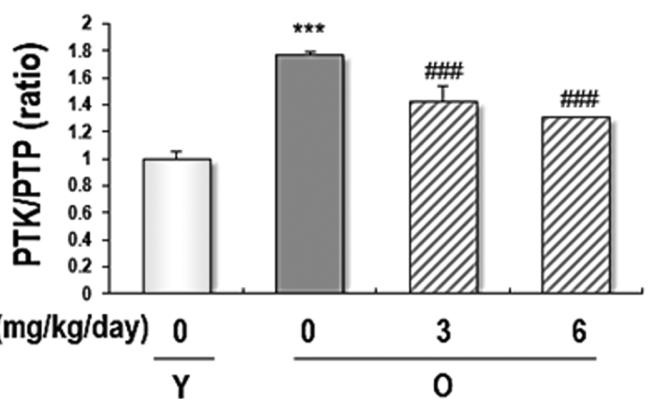

Fig. 5. Reversible effects of ferulate on PTK/PTP activity in the kidneys of aged rats. Kidney homogenates were prepared to detect the PTK (A) and PTP (B) activity, which were then used to determine the PTK/PTP ratio $(C)$ in the kidneys of aged rats. Each value is presented as the mean \pm SD $(n=4)$. The results were analyzed using one-way ANOVA: ${ }^{* * *} p<0.001$ vs young (Y, 7-month-old) rats; ${ }^{\# \#} p<0.01,{ }^{\# \# \#} p<0.001$ vs. untreated aged (O, 20-month-old) rats. suppressed aging-induced activation of PTK and recovered aging-induced inactivation of PTP, both of which resulted in the modulation of the PTK/PTP equilibrium.

We also determined the total activity of PP in the kidney homogenates from aged rats. As shown in Fig. 6A, compared with the activity observed in young rat kidneys, total PP activity was significantly reduced in aged rat kidneys, but kidneys from ferulate-fed aged rats had PP activity that increased in a dose-dependent manner. Additionally, ferulate suppressed aging-induced PP2Ac phosphorylation

(A)

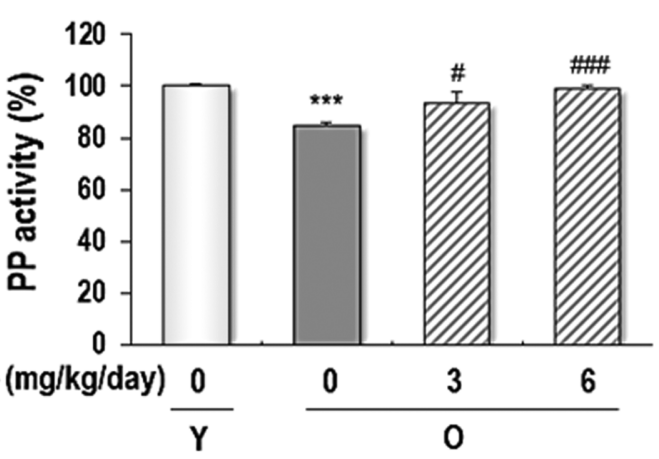

(B)
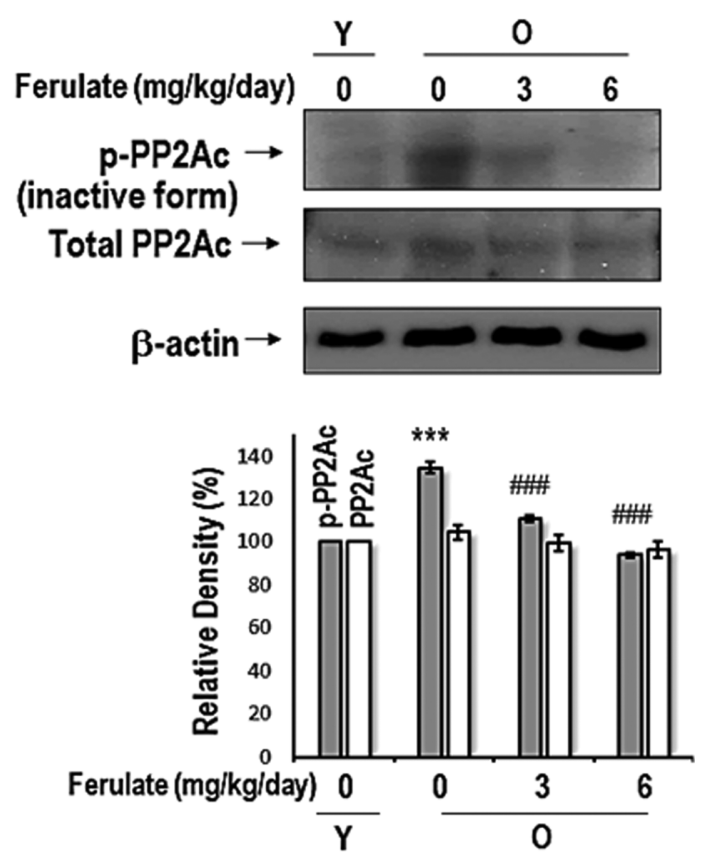

Fig. 6. Reversible effects of ferulate on age-related decreases of total PP activity in the kidneys of aged rats. (A) Kidney homogenates were prepared to measure total PP activity by using a RediPlate 96 EnzChek Serine/Threonine Phosphatase Assay Kit (ThermoFisher Scientific). (B) The levels of phospho-PP2Ac (Tyr307) and total-PP2Ac were detected by western blotting. A representative blot from three independent experiments is shown. $\beta$-Actin was used as a loading control. The results were analyzed using one-way ANOVA: ${ }^{* * *} p<0.001$ vs. young (Y, 7month-old) rats; ${ }^{\#} p<0.05,{ }^{\# \# \#} p<0.001$ vs. untreated aged $(\mathrm{O}$, 20-month-old) rats. 
(Tyr307) in aged rat kidneys; however, there was no change in total PP2Ac expression (Fig. 6B). In conclusion, the present data demonstrated that ferulate ameliorates agerelated oxidative stress-induced PTK/PTP and PP2A inactivation through its antioxidant action. These findings suggest that ferulate could be a regulator of not only cellular redox imbalance but also of PTK/PTP equilibrium.

\section{DISCUSSION}

Ferulate is present in whole-grain wheat, wheat bran, and wheat germ (25) and has been reported to be the major metabolite of hydroxycinnamates (e. g., ferulate, sinapate, p-coumarate, and caffeate) and diferulates (26). Because ferulate is a phenolic compound that contains phenolic structures similar to hydroxyl and phenoxyl groups, ferulate can act as a quenching agent of free radicals (27). In this study, we investigated the effect of ferulate on AAPHinduced and aging-induced inflammation via modulation of PTK and PTP activities.

There is cumulative evidence for the beneficial efficacy of ferulate, and many researchers continue to be intrigued by ferulate's health benefits. Some recent reports describe the activity of ferulate in attenuating acetaminophen-induced liver injury in mice (28), ameliorating trinitrobenzenesulfonic acid (TNBS)-induced ulcerative colitis in rats (29), preventing LPS-induced upregulation of phosphodiesterase 4 (PDE4) activity, assembly of thick bundles of actin filaments (suggesting a potential intervention of neuroinflammatory diseases in the neuroblast cell line PC12) (30), and protecting PK11195-induced mitochondrial apoptosis and cell death in SH-Y5Y neuroblastoma cells (31). Thus, these studies highlight the beneficial effects of ferulate in exerting antioxidant and anti-inflammatory properties.

Owing to the antioxidant properties of phenolic compounds, it is likely that they play a role in protecting the body against oxidative stress and the subsequent effects. In fact, phenolic compounds in grains directly mitigate oxidative stress by increasing the antioxidant capacity in the blood or indirectly via cell signaling $(32,33)$.

The aim of the present study was to elucidate the antiinflammatory effects of ferulate on oxidative stress-related NF- $\kappa \mathrm{B}$ activation. AAPH-treated YPEN-1 cells and aged rat kidneys were prepared as models of oxidative stressinduced inflammation, and we administered ferulate to these models to acquire more evidence of the properties of ferulate. NF- $\kappa \mathrm{B}$ activation can occur via several redoxrelated signaling pathways. Two examples are: IKK $\alpha / \beta-$ dependent I $\mathrm{B} \alpha$ phosphorylation and degradation, which is activated by its upstream MEKKK family NIK $(34,35)$ and MAPKs that induce nuclear translocation, such as ERK, p38 MAPK, and JNK, which are activated by their upstream MEKK (36).

During the aging process, ROS are produced in large quantities because of increased inflammatory reactions. In our previous study, we described a possible mechanism of ROS-induced PTP inhibition and PTK activation via the inflammatory process during aging $(16,22)$. As depicted in Fig. 1, the perturbed balance of PTK/PTP by ROS affected the inactivation of $\mathrm{PP} 2 \mathrm{~A}$, which led to the activation of

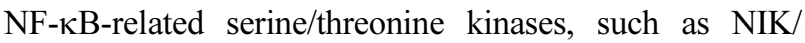
IKKalpha/beta and MAPKs. Therefore, decreases in PP2A activity either directly or indirectly modulate NF- $\mathrm{BB}$ activity. In the present study, inactivation of PP2A by ROS or aging was closely correlated with phosphorylation of Tyr307 on the catalytic subunit of PP2A (PP2Ac), which is consistent with the increase in PTK activity induced by ROS or aging in conjunction with reduced PTP activity. As an antioxidative and anti-inflammatory phenolic compound, ferulate exerted an inhibitory role against PTK and PP2A in the present study. Interestingly, this activity was potent and non-toxic, yet not specific. Additionally, these inhibitory regulations were deemed consistent with the pre-



Ferulate is a low toxicity compound, with $\mathrm{LD}_{50}$ values of $2,445 \mathrm{mg} / \mathrm{kg}$ and $2,113 \mathrm{mg} / \mathrm{kg}$ in male and female rats, respectively (37). Choi et al. (38) found that a ferulate treatment up to $1.54 \mathrm{mM}$ did not show any toxicity on NIH-3T3, HepG2, or 3T3-L1 cells. Additionally, $5.1 \mathrm{mM}$ ferulate treatment for 7 days did not exhibit toxicity on human bone marrow stromal cells (39). In addition, our previous study found that $200 \mu \mathrm{M}$ ferulate inhibited t-BHP-induced cytotoxicity on YPEN-1 cell (11). Furthermore, we have not noticed any adverse reactions in this study. Therefore, ferulate does not seem to have toxic effects on YPEN-1 cells and aged rats.

In conclusion, the modulatory function of ferulate against proinflammatory NF- $\mathrm{KB}$ signaling was demonstrated, and the predicted underlying mechanisms were investigated in this study. The data indicated that ferulate modulated the PTK/PTP balance against oxidative stress-exacerbated inactivation of PTP and PP2A, both of which are directly involved in NF- $\kappa \mathrm{B}$ activation in the AAPH-induced cell model and aged rats. Thus, our study supports a novel mode of action of ferulate in the oxidative stress-related inflammatory process.

\section{ACKNOWLEDGMENTS}

This work was supported by a grant from the Korean government, Small and Medium Business Administration (Project No. C0355276), of the Republic of Korea.

\section{CONFLICT OF INTEREST}

The authors declare no potential conflicts of interests.

Received August 25, 2017; Revised June 4, 2018; Accepted July 4, 2018 


\section{REFERENCES}

1. Tee-ngam, P., Nunant, N., Rattanarat, P., Siangproh, W. and Chailapakul, O. (2013) Simple and rapid determination of ferulic acid levels in food and cosmetic samples using paperbased platforms. Sensors (Basel), 13, 13039-13053.

2. Balasubashini, M.S., Rukkumani, R., Viswanathan, P. and Menon, V.P. (2004) Ferulic acid alleviates lipid peroxidation in diabetic rats. Phytother. Res., 18, 310-314.

3. Sung, J.H., Kim, M.O. and Koh, P.O. (2012) Ferulic acid attenuates the focal cerebral ischemic injury-induced decrease in parvalbumin expression. Neurosci. Lett., 516, 146-150.

4. Baskaran, N., Manoharan, S., Balakrishnan, S. and Pugalendhi, P. (2010) Chemopreventive potential of ferulic acid in 7,12-dimethylbenz[a]anthracene-induced mammary carcinogenesis in Sprague-Dawley rats. Eur. J. Pharmacol., 637, 22-29.

5. Fong, Y., Tang, C.C., Hu, H.T., Fang, H.Y., Chen, B.H., Wu, C.Y., Yuan, S.S., Wang, H.D., Chen, Y.C., Teng, Y.N. and Chiu, C.C. (2016) Inhibitory effect of trans-ferulic acid on proliferation and migration of human lung cancer cells accompanied with increased endogenous reactive oxygen species and beta-catenin instability. Chin. Med., 11, 45.

6. Liang, Q., Ju, Y., Chen, Y., Wang, W., Li, J., Zhang, L., Xu, H., Wood, R.W., Schwarz, E.M., Boyce, B.F., Wang, Y. and Xing, L. (2016) Lymphatic endothelial cells efferent to inflamed joints produce iNOS and inhibit lymphatic vessel contraction and drainage in TNF-induced arthritis in mice. Arthritis Res. Ther., 18, 62.

7. Yang, H., Qu, Z., Zhang, J., Huo, L., Gao, J. and Gao, W. (2016) Ferulic acid ameliorates memory impairment in dgalactose-induced aging mouse model. Int. J. Food Sci. Nutr., 67, 806-817.

8. Navarrete, S., Alarcon, M. and Palomo, I. (2015) Aqueous extract of Tomato (Solanum lycopersicum L.) and ferulic acid reduce the expression of TNF-alpha and IL-1beta in LPS-activated macrophages. Molecules, 20, 15319-15329.

9. Lampiasi, N. and Montana, G. (2016) The molecular events behind ferulic acid mediated modulation of IL-6 expression in LPS-activated Raw 264.7 cells. Immunobiology, 221, 486493.

10. He, G.Y., Xie, M., Gao, Y. and Huang, J.G. (2015) Sodium ferulate attenuates oxidative stress induced inflammation via suppressing NALP3 and NF-kappaB signal pathway. Sichuan Da Xue Xue Bao Yi Xue Ban, 46, 367-371.

11. Jung, K.J., Go, E.K., Kim, J.Y., Yu, B.P. and Chung, H.Y. (2009) Suppression of age-related renal changes in NF-kap$\mathrm{paB}$ and its target gene expression by dietary ferulate. $J$. Nutr. Biochem., 20, 378-388.

12. Banning, A. and Brigelius-Flohe, R. (2005) NF-kappaB, $\mathrm{Nrf2}$, and HO-1 interplay in redox-regulated VCAM-1 expression. Antioxid. Redox. Signal., 7, 889-899.

13. Karin, M. and Ben-Neriah, Y. (2000) Phosphorylation meets ubiquitination: the control of NF-[kappa]B activity. Аnпu. Rev. Immunol., 18, 621-663.

14. Reuter, S., Gupta, S.C., Chaturvedi, M.M. and Aggarwal, B.B. (2010) Oxidative stress, inflammation, and cancer: how are they linked? Free Radic. Biol. Med., 49, 1603-1616.

15. Kim, H.J., Jung, K.J., Yu, B.P., Cho, C.G., Choi, J.S. and
Chung, H.Y. (2002) Modulation of redox-sensitive transcription factors by calorie restriction during aging. Mech. Ageing. Dev., 123, 1589-1595.

16. Jung, K.J., Lee, E.K., Yu, B.P. and Chung, H.Y. (2009) Significance of protein tyrosine kinase/protein tyrosine phosphatase balance in the regulation of NF-kappaB signaling in the inflammatory process and aging. Free Radic. Biol. Med., 47, 983-991.

17. Chiarugi, P. (2005) PTPs versus PTKs: the redox side of the coin. Free Radic. Res., 39, 353-364.

18. Mustelin, T., Vang, T. and Bottini, N. (2005) Protein tyrosine phosphatases and the immune response. Nat. Rev. Immunol., 5, 43-57.

19. Frijhoff, J., Dagnell, M., Godfrey, R. and Ostman, A. (2014) Regulation of protein tyrosine phosphatase oxidation in cell adhesion and migration. Antioxid. Redox. Signal., 20, 19942010.

20. Barisic, S., Schmidt, C., Walczak, H. and Kulms, D. (2010) Tyrosine phosphatase inhibition triggers sustained canonical serine-dependent NFkappaB activation via Src-dependent blockade of PP2A. Biochem. Pharmacol., 80, 439-447.

21. Duan, Y., Chen, F., Zhang, A., Zhu, B., Sun, J., Xie, Q. and Chen, Z. (2014) Aspirin inhibits lipopolysaccharide-induced COX-2 expression and PGE2 production in porcine alveolar macrophages by modulating protein kinase $\mathrm{C}$ and protein tyrosine phosphatase activity. BMB Rep., 47, 45-50.

22. Jung, K.J., Kim, D.H., Lee, E.K., Song, C.W., Yu, B.P. and Chung, H.Y. (2013) Oxidative stress induces inactivation of protein phosphatase $2 \mathrm{~A}$, promoting proinflammatory NFkappaB in aged rat kidney. Free Radic. Biol. Med., 61, 206217.

23. Witt, J., Barisic, S., Schumann, E., Allgower, F., Sawodny, O., Sauter, T. and Kulms, D. (2009) Mechanism of PP2Amediated IKK beta dephosphorylation: a systems biological approach. BMC Syst. Biol., 3, 71.

24. Guy, G.R., Philp, R. and Tan, Y.H. (1995) Activation of protein kinases and the inactivation of protein phosphatase $2 \mathrm{~A}$ in tumour necrosis factor and interleukin-1 signal-transduction pathways. Eur. J. Biochem., 229, 503-511.

25. Dobberstein, D. and Bunzel, M. (2010) Separation and detection of cell wall-bound ferulic acid dehydrodimers and dehydrotrimers in cereals and other plant materials by reversed phase high-performance liquid chromatography with ultraviolet detection. J. Agric. Food Chem., 58, 8927-8935.

26. Kern, S.M., Bennett, R.N., Needs, P.W., Mellon, F.A., Kroon, P.A. and Garcia-Conesa, M.T. (2003) Characterization of metabolites of hydroxycinnamates in the in vitro model of human small intestinal epithelium caco-2 cells. $J$. Agric. Food Chem., 51, 7884-7891.

27. Graf, E. (1992) Antioxidant potential of ferulic acid. Free Radic. Biol. Med., 13, 435-448.

28. Yuan, J., Ge, K., Mu, J., Rong, J., Zhang, L., Wang, B., Wan, J. and Xia, G. (2016) Ferulic acid attenuated acetaminopheninduced hepatotoxicity though down-regulating the cytochrome P 2E1 and inhibiting toll-like receptor 4 signalingmediated inflammation in mice. Am. J. Transl. Res., 8, 42054214.

29. Sadar, S.S., Vyawahare, N.S. and Bodhankar, S.L. (2016) Ferulic acid ameliorates TNBS-induced ulcerative colitis 
through modulation of cytokines, oxidative stress, iNOs, COX-2, and apoptosis in laboratory rats. EXCLI J., 15, 482499.

30. Huang, H., Hong, Q., Tan, H.L., Xiao, C.R. and Gao, Y. (2016) Ferulic acid prevents LPS-induced up-regulation of PDE4B and stimulates the CAMP/CREB signaling pathway in PC12 cells. Acta Pharmacol. Sin., 37, 1543-1554.

31. Wu, Y., Shamoto-Nagai, M., Maruyama, W., Osawa, T. and Naoi, M. (2017) Phytochemicals prevent mitochondrial membrane permeabilization and protect SH-SY5Y cells against apoptosis induced by PK11195, a ligand for outer membrane translocator protein. J. Neural Transm. (Vienna), 124, 89-98.

32. Ursini, F., Maiorino, M. and Forman, H.J. (2016) Redox homeostasis: The Golden Mean of healthy living. Redox Biol., 8, 205-215.

33. Surh, Y.J., Kundu, J.K., Na, H.K. and Lee, J.S. (2005) Redox-sensitive transcription factors as prime targets for chemoprevention with anti-inflammatory and antioxidative phytochemicals. J. Nutr., 135, 2993S-3001S.

34. Schmitz, M.L. and Baeuerle, P.A. (1995) Multi-step activa- tion of NF-kappa B/Rel transcription factors. Immunobiology, 193, 116-127.

35. Greten, F.R. and Karin, M. (2004) The IKK/NF-kappaB activation pathway-a target for prevention and treatment of cancer. Cancer Lett., 206, 193-199.

36. Liu, H.S., Pan, C.E., Liu, Q.G., Yang, W. and Liu, X.M. (2003) Effect of NF-kappaB and p38 MAPK in activated monocytes/macrophages on pro-inflammatory, cytokines of rats with acute pancreatitis. World J. Gastroenterol., 9, 25132518.

37. Mancuso, C. and Santangelo, R. (2014) Ferulic acid: pharmacological and toxicological aspects. Food Chem. Toxicol., 65, 185-195.

38. Choi, J.H., Park, J.K., Kim, K.M., Lee, H.J. and Kim, S. (2018) In vitro and in vivo antithrombotic and cytotoxicity effects of ferulic acid. J. Biochem. Mol. Toxicol., 32, e22004.

39. Wang, Y., Deng, Z., Lai, X. and Tu, W. (2005) Differentiation of human bone marrow stromal cells into neural-like cells induced by sodium ferulate in vitro. Cell Mol. Immunol., 2, 225-229. 